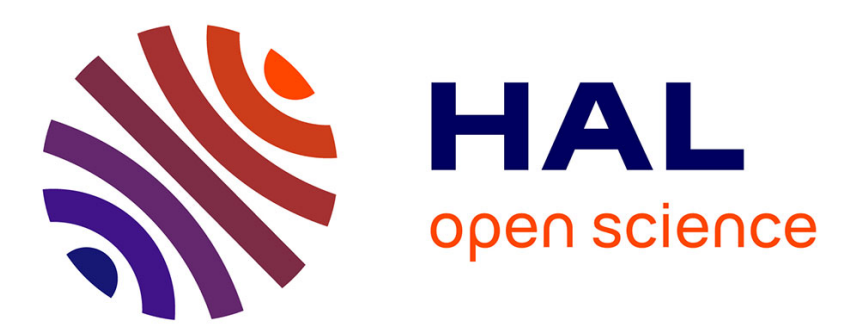

\title{
An embedded portable biosensor system for bacterial concentration detection
}

Marco Grossi, Massimo Lanzoni, Anna Pompei, Roberto Lazzarini, Diego

Matteuzzi, Bruno Riccò

\section{- To cite this version:}

Marco Grossi, Massimo Lanzoni, Anna Pompei, Roberto Lazzarini, Diego Matteuzzi, et al.. An embedded portable biosensor system for bacterial concentration detection. Biosensors and Bioelectronics, 2010, 26 (3), pp.983-990. 10.1016/j.bios.2010.08.039 . hal-01276579

HAL Id: hal-01276579

https://hal.science/hal-01276579

Submitted on 25 Feb 2016

HAL is a multi-disciplinary open access archive for the deposit and dissemination of scientific research documents, whether they are published or not. The documents may come from teaching and research institutions in France or abroad, or from public or private research centers.
L'archive ouverte pluridisciplinaire HAL, est destinée au dépôt et à la diffusion de documents scientifiques de niveau recherche, publiés ou non, émanant des établissements d'enseignement et de recherche français ou étrangers, des laboratoires publics ou privés. 


\title{
An embedded portable biosensor system for bacterial concentration detection
}

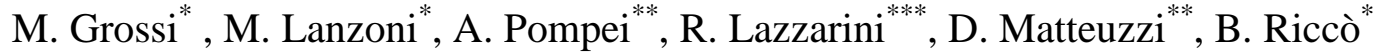 \\ Corresponding author : marco.grossi8@unibo.it, Tel. 0039-0512093082, Fax 0039-0512093785 \\ * Department of Electronic Engineering (D.E.I.S.), University of Bologna, Bologna, Italy \\ ** Department of Pharmaceutical Sciences, University of Bologna, Bologna, Italy \\ *** Carpigiani S.P.A., Anzola Emilia, Bologna, Italy
}

\begin{abstract}
Microbial screening is a primary concern for many products. Traditional techniques based on standard plate counts (SPC) are accurate, but time consuming. Furthermore, they require a laboratory environment and qualified personnel. The Impedance Technique (IT) looking for changes in the electrical characteristics of the Sample Under Test (SUT) induced by bacterial metabolism represents an interesting alternative to SPC since it is faster (3-12 hours vs 24-72 hours for SPC) and can be easily implemented in automatic form. With this approach, the essential parameter is the time for bacteria concentration to reach a critical threshold value (about $10^{7}$ $\mathrm{cfu} \cdot \mathrm{mL}^{-1}$ ) capable of inducing significant variations in the SUT impedance, measured by applying a $100 \mathrm{mV}$ peak to peak $200 \mathrm{~Hz}$ sinusoidal test signal at time intervals of 5 minutes. The results of this work show good correlation between data obtained with the SPC approach and with impedance measurements lasting only 3 hours, in the case of highly contaminated samples $\left(10^{6} \mathrm{cfu} \cdot \mathrm{mL}^{-1}\right)$. Furthermore, this work introduces a portable system for impedance measurements composed of an incubation chamber containing the SUT, a thermoregulation board to control the target temperature and an impedance measurement board. The mix of cheap electronics and fast detection time provides a useful tool for microbial screening in industrial and commercial environments.
\end{abstract}

Keywords : portable biosensor, embedded system, bacterial count, impedance, food safety 


\section{Introduction}

The need for microbial screening is a primary concern for various market segments, such as, for example, the medical, environmental, food and military ones (Alocilja and Radke, 2003). In the food industry, in particular, microbial tests are performed to screen the product for dangerous pathogens as well as to guarantee that the total microbial concentration is below the allowed threshold values. At this regard, it is estimated that each year food is responsible for 76 million cases of illness in the US, resulting in 325000 hospitalizations and 5000 deaths (Mead et al., 2000). Similar problems are encountered with drinking water, progressively more exposed to microbial contamination, hence necessarily subject to different treatments (such as filtering and chlorination) to eliminate pathogens.

Microbial concentration is traditionally measured by means of the standard plate count (SPC) technique (Kaspar and Tartera, 1990), performed by inoculating the culture plate with a dilute solution of the sample under test (SUT) and counting the number of cells grown in the resultant culture. This approach is characterized by high accuracy but it features long times ( 24 to 72 hours, depending on culture broth and bacteria type) and, in practice, requires a microbiology laboratory with qualified personnel.

In the recent years a large effort has been spent on the search for innovative techniques capable of faster responses. To this purpose, several methods have been developed based on bioluminescence (Stanley, 2005), amperometry (Perez et al., 2001), impedance (Suehiro et al., 2003), turbidity (Koch, 1970), piezoelectricity (Plomer et al., 1992), optical waveguide (Zourob et al., 2007) and flow cytometry (Gunasekera et al., 2000). All these are highly competitive with SPC in terms of time response (from 20 minutes to few hours), but require rather complex procedures making them

unsuitable for applications outside microbiology laboratory (in addition, those exploiting turbidity are only applicable to non opaque samples). In particular, piezoelectric immunosensors are characterized by fast detection times $(30-50$ minutes) but do not exhibit enough sensitivity and 
repeatability for industrial applications. In those based on bioluminescence (exploiting the ability of certain bacterial species to emit photons as a byproduct of their reactions) sensitivity and time response is strongly dependent on bacteria strain, while those making use of optical waveguides, although fast $(<1$ hour $)$, generally do not have sufficient sensitivity $\left(\approx 10^{4} \mathrm{cfu} \cdot \mathrm{mL}^{-1}\right)$. Flow citometry, used in the commercial instrument Bactoscan (by Foss Electric) for total bacterial concentration of raw milk samples (Lachowsky et al., 1997), has short response times (20 minutes), but is very expensivet (100.000 to 150.000 USD depending on the model), hence can be used only by big production centers with advanced quality control laboratories.

On the other hand, the Impedance Technique (IT) based on the monitoring of changes in the SUT electrical characteristics induced by bacterial metabolism (Fistemberg-Eden and Eden, 1984) provides a good solution for many cases of practical interest, since it: a) measures total bacterial concentration with response time ranging from 3 to 12 hours (depending on the sample microbial concentration); b) can be easily implemented in automated form with cheap electronics.

Impedance microbiology was introduced by G.N. Stewart at a meeting of the British Medical Association at Edinburgh in July 1898, and later described in a published paper (Stewart, 1899). Only in the mid seventies, however, this technique began to receive attention, with a consequent increase in published work (Ur and Brown , 1973 , 1974 , 1975 ; Cady , 1975). The IT essentially works as follows (Cady et al., 1978 ; Silley and Forsythe, 1996): the SUT is incubated at a temperature favoring bacterial growth (in the range $30{ }^{\circ} \mathrm{C}-40{ }^{\circ} \mathrm{C}$ for total mesophilic bacterial count) and, at regular intervals, the electrical characteristics (namely $|Z|$ and $\operatorname{Arg}(Z)$ ) are measured. As discussed elsewhere (Grossi et al., 2008 , 2009), the system composed by the SUT and a couple of electrodes stimulated with a low frequency sinusoidal voltage can be modeled by means of the series of a resistance (accounting for the conductivity of the medium and of the electrode/electrolyte interface) and a capacitance (due to the double layer present at the electrode/electrolyte interface). After the time needed for stabilization, both the $\mathrm{Z}$ resistive and reactive components remain essentially constant (at a "baseline" value) until the bacterial concentration in the SUT reaches a 
threshold value (in the order of $10^{7} \mathrm{cfu} \cdot \mathrm{mL}^{-1}$ ) sufficient to induced appreciable changes in the sample electrical characteristics. When such a condition is reached, both the $\mathrm{Z}$ components begin to decrease. As pointed out in (Grossi et al., 2008), the choice to monitor the $\mathrm{Z}$ resistive or reactive component depends on the SUT chemical composition, since normally one of the components provides more reliable results than the other. The time at which the electrical parameters begin to deviate from their baseline value is called Detect Time (DT) and, since DT has a linear relationship with the logarithm of bacterial concentration, this latter can be easily worked out. The main drawback of the IT is that, since bacterial concentration is calculated by measuring the time needed for the microbial population to reach a threshold concentration, the measurements time depends strongly on the time needed for a cell to duplicate of the bacterial strains of interest. Thus the need to correctly choose the incubation temperature in order to minimize differences in generation times of different microbial species possibly present in the SUT.

At present, the IT technique is used for microbial evaluation by different commercial systems such as Bactometer by Vitek Systems Ltd. (Basingstoke, UK), Malthus by Malthus Instruments Ltd. (Bury, UK), RABIT by Don Whitley Scientific (Shipley, UK), Bac Trac by Sy-Lab (Purkensdorf, Austria). All these systems are based on the same principles and differ essentially for the materials used for the electrodes (stainless steel or platinum) and the frequency of the applied test signal. All of them feature a thermal chamber to contain the SUT, acquisition system for measuring the electric parameters and software for proper interpretation of the data and estimation of the bacterial concentration. However, all the systems are benchtop instruments, only suitable for laboratory environments and skilled personnel.

This paper, instead, describes a portable biosensor system for bacterial concentration detection based on the IT, that is fully automated and requires no particular knowledge of microbiological techniques, thus making it particularly suitable for microbial screening in industrial or commercial environments. Moreover, the use of cheap electronics makes it highly competitive in terms of cost (few hundreds USD). 


\section{Experimental design}

The portable biosensor system described in this work, represented in Fig. 1, features two circuit boards: one, dedicated at maintaining the SUT at the target temperature by means of an ad hoc algorithm running on the microcontroller ATmega168 by Atmel (California , USA); the other, based on the microcontroller ARM STR912 by STMicroelectronics (Agrate Brianza, Italy), is used for signal analysis and the calculation of the impedance and its components. The SUT incubation chamber features a couple of stainless steel electrodes for the electrical measures, a temperature sensor and a heating system for thermal regulation.

The system works as follows. First the incubation chamber is sterilized with a portable steam cleaner at $100{ }^{\circ} \mathrm{C}$ for 10 minutes to eliminate any residual bacterial population. The efficiency of the sterilization procedure has been tested by means of SPC with samples taken from the chamber with cotton plugs. The measured bacterial concentration after sterilization has always been found < $10 \mathrm{cfu} \cdot \mathrm{mL}^{-1}$ (minimal concentration detected). Even if a minimal number of bacterial spores survives the sterilization process, the time for them to grow to high concentration levels would be of several days: thus their presence doesn't interfere with the successive measurements.

Then, after the start command, the thermoregulation board is enabled to keep the incubation chamber at a target temperature. The impedance measurement board waits (30 minutes) for the sample temperature to stabilize, then start measuring the SUT electrical characteristics at time intervals of 5 minutes. When the electrical parameter selected for monitoring deviates from its baseline value for more than $5 \%$ the assay stops and the value of DT is calculated.

Serial communication between the system boards and a PC laptop allows a graphical representation of the measured electrical parameters and temperature as well as data filing. The serial interface make is also possible to set the parameters of interest (target temperature, thermoregulator parameters, assay duration, value of DT to discriminating acceptable and contaminated sample, etc.). 
Finally, a GT 863-PY terminal by Telit (Trieste, Italy) controlled by the impedance measurement board allows wireless communications for remote data transfer.

In the following a detailed description is given of the main parts of the developed biosensor system.

\subsection{Incubation chamber}

The SUT incubation chamber, shown in Fig. 2 (a) and (b), features a volume capacity of $4 \mathrm{ml}$. The electrical measurements are made using a couple of cap-shaped stainless steel electrodes $(5 \mathrm{~mm}$ diameter, separated by $4.5 \mathrm{~mm}$ ) placed in direct contact with the tested sample. The material of the electrodes is very important, since metal ions released into the sample can be toxic to bacteria and inhibit their growth. From this point of view platinum and stainless steel electrodes have been found to have no negative effect at low applied field, while silver and gold electrodes exhibit bacteriostatic properties (Spadaro et al., 1974). In our case, stainless steel has been chosen because of its low cost and good behavior when measuring both the resistive and reactive $\mathrm{Z}$ components.

The electrode-electrolyte system can be modeled as shown in Fig. 2 (c) (Sengupta et al., 2006). The ions in the electrolyte are subjected to different electrical forces on the electrode and bulk side of the structure, thus leading to the formation of a double layer region at the electrode-electrolyte interface. The system electrical behavior can be modeled with the equivalent circuit shown in Fig. 2 (c), where $\mathrm{R}_{\mathrm{i}}$ and $\mathrm{C}_{\mathrm{i}}$ represent the resistive and capacitive components of the double layer interface, respectively, while $R_{m}$ and $C_{m}$ are the corresponding components of the tested media (bulk electrolyte). However, when the frequency of the applied test signal is low enough $(<1 \mathrm{MHz})$ (Grossi et al., 2008), $\mathrm{C}_{\mathrm{m}}$ can be neglected and the equivalent circuit is simply reduced to the series of a resistance $\left(\mathrm{R}_{\mathrm{s}}\right)$ and a capacitance $\left(\mathrm{C}_{\mathrm{s}}\right)$, as anticipated in the introduction.

Temperature regulation is obtained with a couple of adhesive power resistance (24 Ohm, 15 Watt maximum power, $24 \mathrm{~V} 50 \mathrm{~Hz}$ power supply) applied to the chamber outer wall. The SUT temperature is continuously monitored by means of sensors reaching the chamber interior. Two different sensors have been used to this purpose. The first (and default one) is a three terminals 
precision temperature sensor LM135 (National Semiconductor, Santa Clara, CA, USA) operating as a Zener diode with a breakdown voltage directly proportional to the absolute temperature and a slope equal to $10 \mathrm{mV} /{ }^{\circ} \mathrm{K}$. This sensor features a temperature range from $-55{ }^{\circ} \mathrm{C}$ to $150{ }^{\circ} \mathrm{C}$ and allows calibration for high accuracy measurements. The other sensor is a platinum resistance temperature detector (PT100) working on a broad range of temperatures $\left(-200\right.$ to $\left.+850{ }^{\circ} \mathrm{C}\right)$ and whose resistance is linearly related to the temperature.

\subsection{Thermoregulation board}

The thermoregulation board maintains the SUT at the target temperature: since the measured electrical parameters are strongly temperature dependent, the regulation needs to be very accurate. Our board, developed "ad hoc" is capable of maintaining the target temperature with an accuracy of $\pm 0.15^{\circ} \mathrm{C}$ by means of a proportional-integral-derivative (PID) software algorithm.

A schematic of the thermoregulation board is presented in Fig. 3 (a). Starting from the standard supply (featuring $50 \mathrm{~Hz}$ and $230 \mathrm{~V}$ ), a voltage transformer generates a $50 \mathrm{~Hz} 13 \mathrm{~V}$ sinusoidal voltage that is used for the power heater. This voltage is also rectified by a bridge diode circuit and fed to the voltage regulator L78M05 (STMicroelectronics, Italy) to generate the $5 \mathrm{~V}$ DC supply for both the system boards. The DSP AN221E04 (Anadigm, USA) is used for conditioning (ADC conversion and signal filtering) the temperature signals that are send to the microcontroller ATmega168 to be analyzed. The microcontroller generates the Gate Control (GC) signal driving an optoisolator-triac stage in order to supply the power heater according to the measured temperature. The GC signal has a duration of 2 seconds and its duty cycle is calculated according to an algorithm. Given $\mathrm{T}^{*}$ the target temperature to be reached and $\mathrm{e}(\mathrm{t})$ the error function defined as the difference between target and measured temperatures, the duty cycle of GC signal is calculated on the basis of the analog function $\mathrm{u}(\mathrm{t})$ :

$$
u(t)=K_{P} e(t)+K_{I} \int_{0}^{t} e(\tau) d \tau+K_{D} \frac{d e(t)}{d t} .
$$


Since the thermoregulator board samples the signal at regular intervals of $\Delta t=2$ sec and the ATmega168 microcontroller works on 16 bit digital signals, the analog-values time-continuous function in (1) must be converted in its discrete-values time-discrete counterpart. This is done by deriving both side of (1) and replacing the derivative functions with the corresponding incremental ratio. Thus :

$u_{K}=u_{K-1}+K_{P}\left(e_{K}-e_{K-1}\right)+K_{I} e_{K} \Delta t+K_{D} \frac{e_{K}-2 e_{K-1}+e_{K-2}}{\Delta t}$

The GC duty cycle for the k-th cycle is thus calculated as $\mathrm{u}_{\mathrm{K}}$ if $0 \leq \mathrm{u}_{\mathrm{K}} \leq 100,0$ if $\mathrm{u}_{\mathrm{K}}<0$ and 100 if $\mathrm{u}_{\mathrm{K}}>100$. A correct choice of the thermoregulator parameters is thus mandatory to guarantee good dynamic performance of the sample temperature. A too high value for $\mathrm{K}_{\mathrm{I}}$ results in an oscillatory dynamic while the lack of integral term $\left(\mathrm{K}_{\mathrm{I}}=0\right)$ prevents the sample to reach the target temperature. The PID set $\mathrm{K}_{\mathrm{P}}=5 \mathrm{~K}^{-1}, \mathrm{~K}_{\mathrm{I}}=0.1 \mathrm{~K}^{-1} \cdot \mathrm{s}^{-1}, \mathrm{~K}_{\mathrm{D}}=0 \mathrm{~K}^{-1} \cdot \mathrm{s}$ results in good dynamic performance with fast transient response and almost no overshoot on the target temperature.

The effect of a bad choice for the thermoregulator parameters (resulting in sample temperature oscillation of $3.5^{\circ} \mathrm{C}$ for target temperature of $35^{\circ} \mathrm{C}$ ) is shown in Fig. 3 (b) and (c), where the resistive and capacitive components of the sensor impedance are plotted vs time in the case of a vanilla flavored ice-cream sample inoculated with $70 \mathrm{cfu} \cdot \mathrm{mL}^{-1}$ Escherichia coli ATCC 11105 from American Type Culture Collection. As can be seen, the resistive impedance component (12\% variation) is influenced by temperature oscillation much more than the capacitive one (5\% variation). However, in both cases the oscillation is large enough to trigger the end of the assay (5\% variation on baseline value), thus preventing a reliable estimation of DT (hence, also of microbial concentration).

\subsection{Impedance measurement board}

The impedance measurement board acquires the electrical characteristics of the sample at regular intervals and calculates the DT (and from this data it infers the bacterial concentration) at the end of the assay. Fig. 4 (a) shows a schematic of the board with its main components. The AD9833 
(Analog Devices, USA) programmable waveform generator provides the $100 \mathrm{mV}$ peak-to-peak, 200 $\mathrm{Hz}$ voltage test signal $\left(\mathrm{V}_{\text {in }}\right)$ (for the reasons for this parameter choice see Grossi et al., 2008). The test signal is applied to the electrodes only when the electrical characteristics are measured, while between inter-measurements time ( 5 minutes) the electrodes are disconnected from the system by a couple of relais G6J-2FS-Y (Omron, Japan) to prevent charging of the sample-electrode interface resulting in parameter drift, long time for baseline stabilization and, in general, difficult DT calculation (Felice et al., 2005). The current resulted from the application of $V_{\text {in }}$ is measured by means of the $\mathrm{I}-\mathrm{V}$ converter, providing an output $\left(\mathrm{V}_{\text {out }}\right)$ proportional to the input current $\left(\mathrm{I}_{\mathrm{in}}\right)$. The $10 \mathrm{~K} \Omega$ digital potentiometer providing the feedback to the $\mathrm{I}-\mathrm{V}$ converter is set before the first measure (after 30 minutes delay) to guarantee that samples characterized by conductivity ranging over a broad interval can be tested with the system. Denoting $R_{\mathrm{f}}$ the resistance of the digital potentiometer, it is $H(j \omega)=\frac{V_{\text {OUT }}(j \omega)}{V_{I N}(j \omega)}=-\frac{R_{f}}{Z_{\text {cell }}}$, thus the electrical characteristics can be calculated with the analysis of $\mathrm{V}_{\text {in }}$ and $\mathrm{V}_{\text {out }}$ voltage waveform. The voltage signals are then fed to a differential 18 bit ADC drivers that, acting as a low-pass filters with cut-off frequency of $1 \mathrm{KHz}$, eliminates high frequency noise before sampling by 16 bit ADC (100 Ksample/sec). Digitized waveform are then fed to the ARM STR912 $\mu$ controller, where software-implemented finite impulse response (FIR) filtering eliminates noise at low frequency (in particular the $50 \mathrm{~Hz}$ line component).

Since, as pointed out in the introduction, the electrodes-media system can be modeled by the series of the resistance $R_{s}$ and the capacitor $C_{s}$, defining $V_{\text {Mout }}$ and $V_{\text {Min }}$ the amplitude of the corresponding sinusoidal signals and $\varphi$ the phase difference of $\mathrm{V}_{\text {in }}$ and $\mathrm{V}_{\text {out }}$, from (Grossi et al., 2008) it is $R_{s}=\frac{V_{\text {Min }}}{V_{\text {Mout }}} R_{f} \cos (\varphi)$ and $C_{s}=\frac{1}{2 \pi f R_{f}} \frac{V_{\text {Mout }}}{V_{\text {Min }}} \frac{1}{\operatorname{sen}(\varphi)}$. Thus, both electrical parameters can be calculated by measuring the amplitude signals ( $\mathrm{V}_{\text {Min }}$ and $\left.\mathrm{V}_{\text {Mout }}\right)$, the phase difference $\varphi$ and the signal frequency $\mathrm{f}$. 
The parameters are estimated by analyzing $V_{\text {in }}(t)$ and $V_{\text {out }}(t)$ signals acquired by the 16 bit ADC : the following functions are calculated :

$$
\begin{array}{ll}
J_{A, \text { in }}=\int_{0}^{T / 2} V_{\text {in }}(t) d t=\frac{V_{\text {Min }}}{\pi f} & , \\
J_{B, \text { in }}=\int_{0}^{T / 2} V^{2}{ }_{\text {in }}(t) d t=\frac{V^{2}{ }_{\text {Min }}}{4 f} & ,
\end{array}
$$

Thus it is :

$$
V_{\text {Min }}=\frac{4}{\pi} \frac{J_{B, \text { in }}}{J_{A, \text { in }}} \quad, \quad V_{\text {Mout }}=\frac{4}{\pi} \frac{J_{B, \text { out }}}{J_{A, \text { out }}} \quad, \quad f=\frac{4}{\pi^{2}} \frac{J_{B, \text { in }}}{J_{A, \text { in }}^{2}} \quad, \quad \cos (\varphi)=\frac{\pi f J_{C}}{V_{\text {Mout }}}
$$

Each measurement is averaged over 192 signal periods, leading to electrical parameter $\left(\mathrm{R}_{\mathrm{s}}\right.$ and $\left.\mathrm{C}_{\mathrm{s}}\right)$ estimation with a precision higher than $99 \%$.

The impedance measurement board also estimates the value of DT at the end of the assay. This is done using an algorithm that approximates the $\mathrm{R}_{\mathrm{s}}$ or $\mathrm{C}_{\mathrm{s}}$ curve with a piecewise linear function composed of three segments. Fig. 4 (b) shows the measured curve as well as the fitting function in the case of $\mathrm{C}_{\mathrm{s}}$ for a vanilla flavored ice-cream sample. The first segment takes in account the initial stabilization before the baseline value is reached; the second (parallel to the $\mathrm{x}$-axis) represents the baseline value, while the last segment represents the increase of $C_{s}$ due to bacterial growth over $10^{7}$ $\mathrm{cfu} \cdot \mathrm{mL}^{-1}$. DT is thus calculated as the intersection of the second and third segment. The procedure to best-fit measured data with the proposed function is based on minimizing the mean square error. Given the general expression of the function :

$$
f(t)=\left\{\begin{array}{crc}
\frac{B-A}{k T} t+A & \text { if } & 0 \leq t \leq k T \\
B & \text { if } & k T<t<h T \\
\frac{C-B}{(N-h) T} t+\frac{B N-C h}{N-h} & \text { if } & h T \leq t \leq N T
\end{array}\right.
$$

where the first segment extremes are $(0, \mathrm{~A})(\mathrm{kT}, \mathrm{B})$, the second segment are $(\mathrm{kT}, \mathrm{B})(\mathrm{hT}, \mathrm{B})$ and the third (hT,B) (NT,C), $\mathrm{T}$ is the time delay between measures and $\mathrm{N}$ is the total number of measures. 
For $\mathrm{k}$ variable between 1 and $\mathrm{N}-2$ and $\mathrm{h}$ between $\mathrm{k}+1$ and $\mathrm{N}-1$, the cost function is computed as $F_{k, h}=\sum_{j=0}^{N}\left(y_{j}-f(j T)\right)^{2}$ where $\mathrm{y}_{\mathrm{j}}$ is the $\mathrm{j}$-th measured value and best-fit values for $\mathrm{A}, \mathrm{B}$ and $\mathrm{C}$ are computed imposing $\frac{\partial F_{k, h}}{\partial A}=\frac{\partial F_{k, h}}{\partial B}=\frac{\partial F_{k, h}}{\partial C}=0$.

With the calculated values for A, B and C the optimal cost function value $\bar{F}_{k, h}$ is determined for all values of $\mathrm{k}$ and $\mathrm{h}$. Then the values $(\bar{k}, \bar{h})$ that minimize $\bar{F}_{k, h}$ are determined and $D T=\bar{h} T$. The proposed algorithm can calculate DT value with a precision of 5 minutes (time delay between measures) and is essentially independent of the variation rate of the monitored electrical parameter once the critical bacterial threshold of $10^{7} \mathrm{cfu} \cdot \mathrm{mL}^{-1}$ is reached.

\section{Results and discussion}

The biosensor system of this work has been used to prove the feasibility of bacterial concentration measure in different types of liquid and semi-liquid media.

Samples of industrial ice-cream have been tested (target temperature $35{ }^{\circ} \mathrm{C}$ ) to monitor the microbial concentration of occasional as well as inoculated species. To this latter purpose, E. coli ATCC 11105 , S. aureus ATCC 6538P, E. faecalis 8043, P. aeruginosa ATCC 9027 (obtained from American Type Culture Collection) are used.

The samples have been tested as are, without any dilution in specific growth media. As previously pointed out (Grossi et al., 2008), when dealing with ice-cream samples, only the capacitive component of the impedance provides reliable results, while the resistive one is influenced by phase separation of the sample occurring during the assay. Thus, only the measured $\mathrm{C}_{\mathrm{s}}$ curve has been considered in this work to determine the DT.

Fig. 5 (a) show the plot of DT vs total bacterial concentration (in logarithmic scale) determined by SPC for ice cream samples with occasional contamination as well as for others intentionally contaminated with known concentration of E. coli ATCC 11105, S. aureus ATCC 6538P and E. 
faecalis 8043 . The corresponding linear regression for the set of measure is DT $=-109.64 \log _{10}\left(C_{0}\right)$ +733.65 and the coefficient of determination is $\mathrm{R}^{2}=0.71$ (the figure shows also the lower and higher limits of DT as function of the microbial concentration inferred by Student t-distribution with a confidence level of $95 \%$ ). From the linear regression line it is also possible to determine the mean generation time $\mathrm{T}_{\mathrm{G}}$ (mean time between cells replication) as discussed in (Grossi et al., 2009): from the measured data it is $\mathrm{T}_{\mathrm{G}}=33$ minutes. Fig. 5 (b) shows the percent increase of $\mathrm{C}_{\mathrm{s}}$ (namely $\left.100\left(C_{s}-C_{s, B A S E L I N E}\right) / C_{s, B A S E L I N E}\right)$ as function of time for different bacterial concentration: higher contaminated samples are characterized by lower values of DT, while sterile sample presents no $\mathrm{C}_{\mathrm{s}}$ variation during the whole assay. Ice cream samples contaminated with known concentrations of $P$. aeruginosa ATCC 9027 resulted in slow growth and measured DT values with poor correlation with the reference SPC $\left(R^{2}<0.5\right)$. The addition of yeast extract in the concentration $3 \mathrm{~g} \cdot \mathrm{L}^{-1}$ resulted in higher correlation with SPC.

The system has also been used to prove the feasibility of bacterial contaminants determination in fresh water samples. In this case, nutrient media must be added to the sample to allow bacteria to reach the critical concentration of $10^{7} \mathrm{cfu} \cdot \mathrm{mL}^{-1}$. Total bacterial concentration has been measured by adding yeast extract in the concentration $3 \mathrm{~g} \cdot \mathrm{L}^{-1}$ (YE 3\%), while selective detection of coliforms has been achieved by enriching water samples with Mc Conkey broth. Fresh water samples have been inoculated with known water contaminants bacteria (E. coli ATCC 11105, E. faecalis ATCC 8043, S. aureus 6538P, P. aeruginosa ATCC 9027).

In the case of water samples both capacitive and resistive components resulted in reliable measurement of bacterial concentration. In Fig. 5 (c) and (d) the percent variation for the resistive and capacitive components $\mathrm{R}_{\mathrm{s}}$ and $\mathrm{C}_{\mathrm{s}}$ are plotted vs time for samples inoculated with different concentration of E. coli using YE 3\% as diluting media. As can be seen, the electrical parameters start to deviate from their baseline values at time related to the initial bacterial concentration (higher the contamination, lower the value of DT) and saturate when the bacterial population reaches a steady state (i.e. cells no longer duplicate because of lack of nutrients and accumulation of toxic 
compounds in the media). The bacterial concentration upon electrical parameters saturation has been measured by SPC and resulted about $10^{9} \mathrm{cfu} \cdot \mathrm{mL}^{-1}$. Fig. 5 indicates that the resistive impedance component exhibits a growth almost twice as large as that of its capacitive counterpart (25\% vs 13\%). The mean generation time calculated from the resistive and capacitive curves, however, are not significantly different (21.6 min for $\mathrm{C}_{\mathrm{s}}$ and $19.5 \mathrm{~min}$ for $\mathrm{R}_{\mathrm{s}}$ ). The value of $\mathrm{T}_{\mathrm{G}}$ is much smaller for water than ice-cream samples (about $20 \mathrm{~min}$ vs $33 \mathrm{~min}$ : this is due to the diluting media YE $3 \%$ ), since this latter medium is an excellent stimulator of bacterial growth, leading to faster cells duplication and more regular curves. Samples inoculated with E. faecalis ATCC 8043 and S. aureus 6538P show a similar behavior to that obtained with E. coli ATCC 11105, with comparable value for generation time and concentration at the end of the measure. Samples inoculated with $P$. aeruginosa ATCC 9027, instead, resulted in lower growth rate $\left(\mathrm{T}_{\mathrm{G}}=25 \mathrm{~min}\right)$ and in general lower concentration at the end of the measure $\left(\approx 10^{8} \mathrm{cfu} \cdot \mathrm{mL}^{-1}\right)$.

Since the coliform group has been extensively used as an indicator of water quality, a medium (Mc Conkey) for selective growth of coliform bacteria has been also tested. Water samples have been diluted in the growth media and tested with our biosensor. The results indicate that also Mc Conkey medium is suitable for electrical detection of bacterial concentration. In particular, the obtained curves, although not as regular as those obtained by diluting with YE 3\%, allow reliable measurements of DT, hence of the sample microbial concentration. The bacterial concentration at the end of the assay has been measured by SPC and resulted $3 \cdot 10^{8} \mathrm{cfu} \cdot \mathrm{mL}^{-1}$.

\section{Conclusions}

In this paper a novel embedded portable biosensor system for determination of bacterial concentration based on impedance measurements has been presented. The system is suitable for applications in the industrial field (in particular the dairy one is of interest here), as well as for environmental monitoring (for instance for the case of water microbial screening). 
The system is composed of an incubation chamber, containing the sample under test, and two electronic boards: one dedicated to measuring the sample electrical characteristics, the other controlling the sample temperature, fixed at a value suitable to enhance bacterial growth.

The developed system has been validated by means of a series of experiments performed on icecream samples (where no additional media for dilution has been used) and fresh water samples (where YE 3\% media was added to monitor total bacterial concentration and Mac Conkey broth for selective growth of coliform strains).

In both cases reliable measurements have been obtained, in good agreement with data obtained by standard plate count, normally used as a reference. As for competitiveness, our system provides much faster results compared with the standard plate count technique ( 3 hours for $10^{6} \mathrm{cfu} \cdot \mathrm{mL}^{-1}$ ).

The greatest advantage of the presented system is that it is portable and low cost. On the contrary, most of the biosensors for microbial concentration determination on the market are essentially benchtop instruments to be used within microbiology laboratories.

A reliable, fast and portable system, such as that presented in this work, presents several advantages, particularly in terms of time since it avoids shipping samples to the laboratory.

Moreover, the low cost and possibility to test the microbial concentration even in small production centers and commercial environments can help in improving quality control for food industries and environmental monitoring.

\section{Acknowledgement}

The authors would like to thank Carpigiani s.p.a. (Anzola Emilia, Italy) for discussions and help in system construction. 


\section{References}

Alocilja, E.C. and Radke, S.M., 2003, Biosens. Bioelectron. , 18 , 841-846.

Cady, P. , 1975 , New Approaches to the Identification of Microorganisms, Wiley, New York , 7399

Cady, P., Dufour, S.W., Shaw, J., Kraeger, S.J. , 1978 , J. Clin. Microbiol. , 7 (3), 265-272

Felice, C.J., Madrid, R.E., Valentinuzzi, M.E., 2005 , Biomed. Eng. OnLine, 4:22.

Firstemberg-Eden, R., Eden, G. , 1984 Impedance Microbiology; Wiley: New York; Volume 3, pp. 154-196.

Grossi, M., Lanzoni, M., Pompei, A., Lazzarini, R., Matteuzzi, D., Riccò, B., 2008 , Biosens. Bioelectron. , 23, 1616-1623.

Grossi, M., Pompei, A., Lanzoni, M., Lazzarini, R., Matteuzzi, D., Riccò, B., 2009 , IEEE Sens. J. , 9 (10), 1270-1276.

Gunasekera T.S., Attfield P.V., Veal D.A., 2000, Appl. Environ. Microbiol., 66 (3) , 1228-1232.

Kaspar, C. W., Tartera, C., 1990, in R. Grigorova \& J.R. Norris eds., Methods in Microbiology, Vol. 22, 497-531, London: Academic Press.

Koch, A. L. , 1970 , Anal. Biochem. , 38, 252-259. 
Lachowsky W.M., McNab W.B., Griffiths M., Odumeru J., 1997 , Food Res. Int., 30 (3) , 273-280

Mead, P.S., Slutsker, L., Dietz, V., McCaig, L.F., Bresce, J.S., Shapiro, C., Griffin, P.M., Tauxe, R.V., 2000, J. Environ. Health, 62.

Perez, F., Tryland, I., Mascini, M., Fiksdal, L. , 2001 , Anal. Chim. Acta , 427, 149-154.

Plomer, M., Guilbault, G.G., Hock, B. , 1992 , Enzyme Microb. Technol. , 14, 230-235.

Sengupta, S., Battigelli, D.A., Chang, H.C., 2006 , Lab Chip, 6, 1-11

Silley, P., Forsythe, S. , 1996 , J. Appl. Bacteriol. , 80, 233-243.

Spadaro, J.A., Berger, T.J., Barranco, S.D., Chapin, S.E., Becker, R.O., 1974, Antimicrob. Agents Chemother., 6 (5), 637-642

Stanley, P. E. , 2005 , J. Biolumin. Chemilumin. , 4, 375-380.

Stewart, G.N. , 1899 , J. Exp. Med. , 4 , 235-243

Suehiro, J., Hamada, R., Noutomi, D., Shutou, M., Hara, M. , 2003 , J. Electrostat. , 57, 157-168.

Ur, A., Brown, D.F.J. , 1973 , ICRS J. Int. Res. Commun. , 1, 37

Ur, A., Brown, D.F.J. , 1974 , Biomed. Eng. , 8, 18-20 
Ur, A., Brown, D.F.J. , 1975 , J. Med. Microbiol. , 8, 19-28

Zourob, M.; Mohr, S.; Goddard, N.J., 2007 , ISSSE , 49-52. 
Fig. 1 Photograph (a) and schematic (b) of the biosensor system presented in this work. The system is composed of an impedance measurement board, a thermoregulation board and an incubation chamber containing the sample under test.

Fig. 2 Front and top view, (a) and (b), respectively, of the incubation chamber. The chamber is provided with a couple of stainless steel electrodes, temperature sensors and Joule effect power heater to maintain the target temperature. (c) Electrical model for the system electrodes-sample.

Fig. 3 Schematic of the thermoregulation board (a). Typical curves of $R_{s}$ and $C_{s}$ vs. time (b and c, respectively) for an assay with temperature oscillation.

Fig. 4 Schematic of the impedance measurement board (a). Typical curve $C_{s}$ vs. time with the piecewise linear for best-fitting (b). Detect Time is calculated as the intersection of the second and third segment.

Fig. 5 Scatter plot representing DT as function of microbial concentration (a) and capacitance growth curves for vanilla flavoured ice-cream samples (b). Resistance and capacitance growth curves (c and d, respectively) for fresh water samples diluted with yeast extract in the concentration $3 \mathrm{~g} \cdot \mathrm{L}^{-1}$ and inoculated with known concentration of Escherichia Coli. 


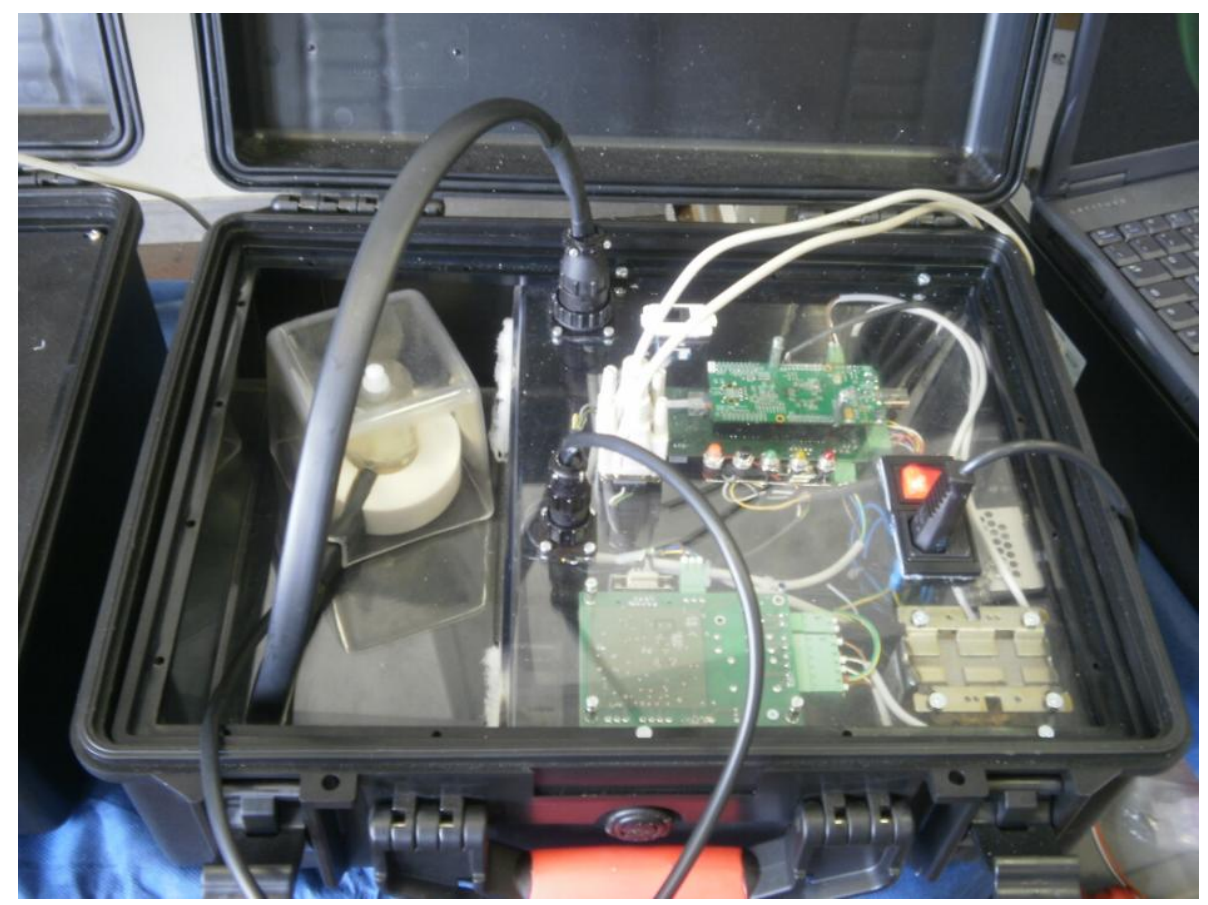

(a)

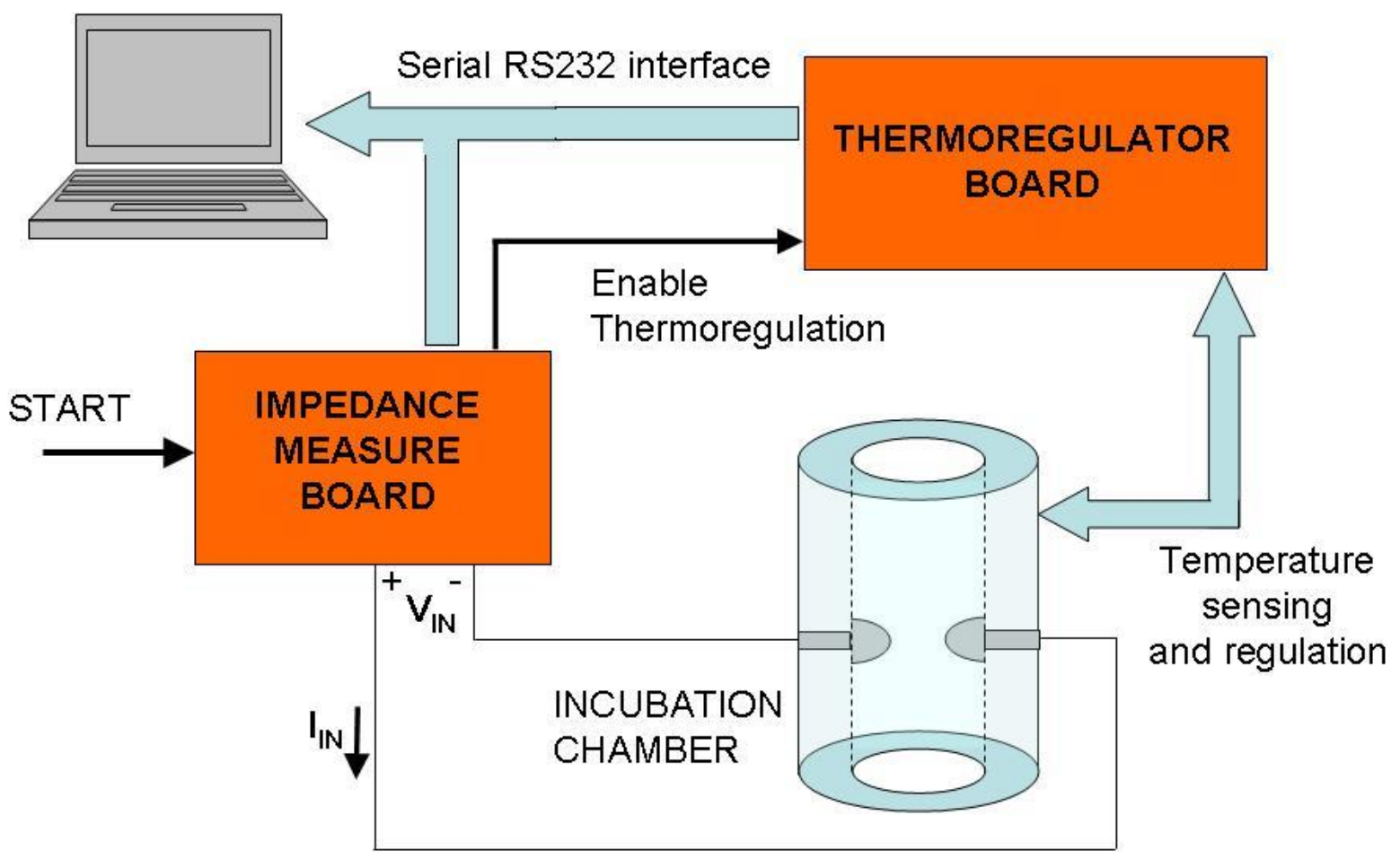

(b)

Fig. 1 


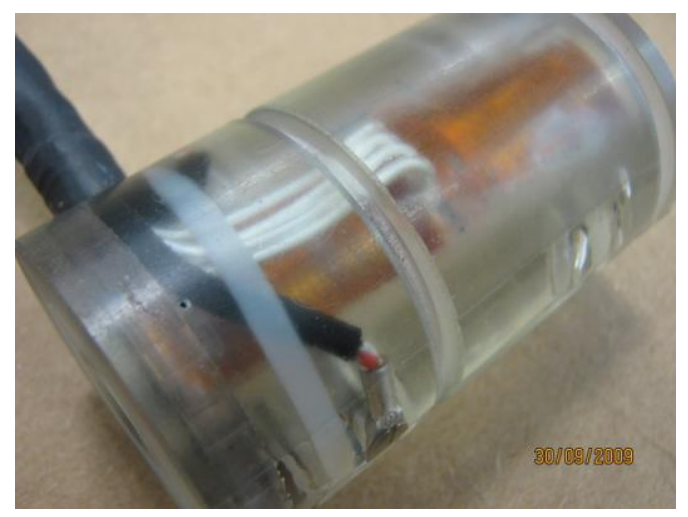

(a)

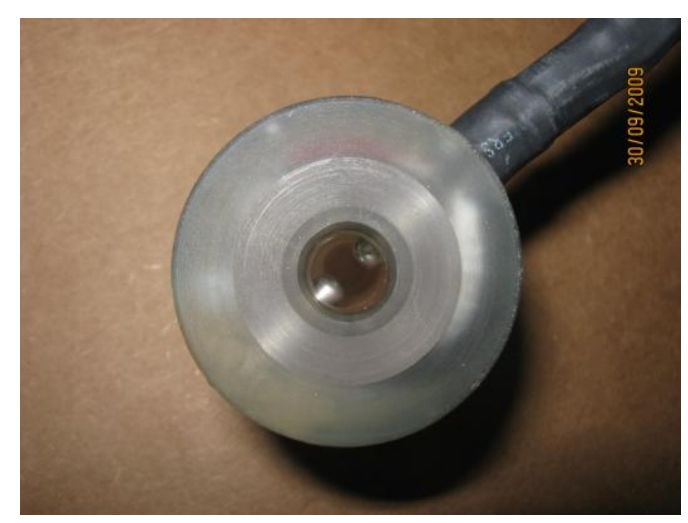

(b)
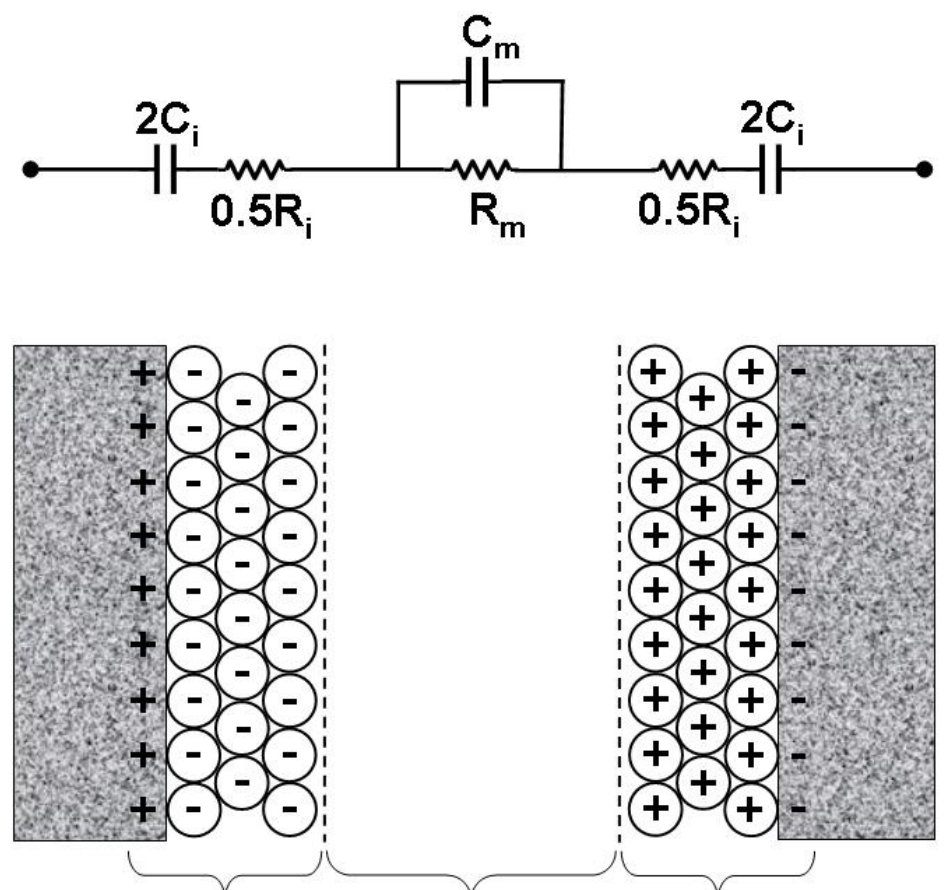

ELECTRODE-ELECTROLYTE BULK ELECTROLYTE INTERFACE

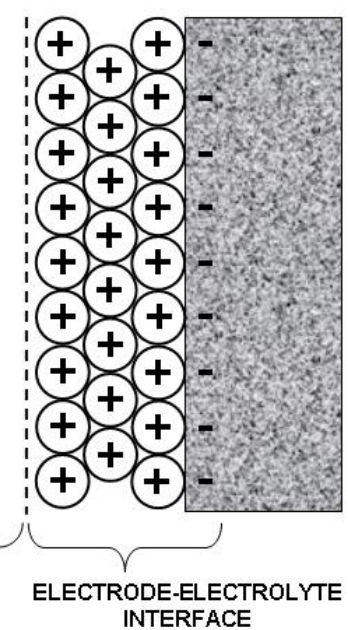

(c)

Fig. 2 


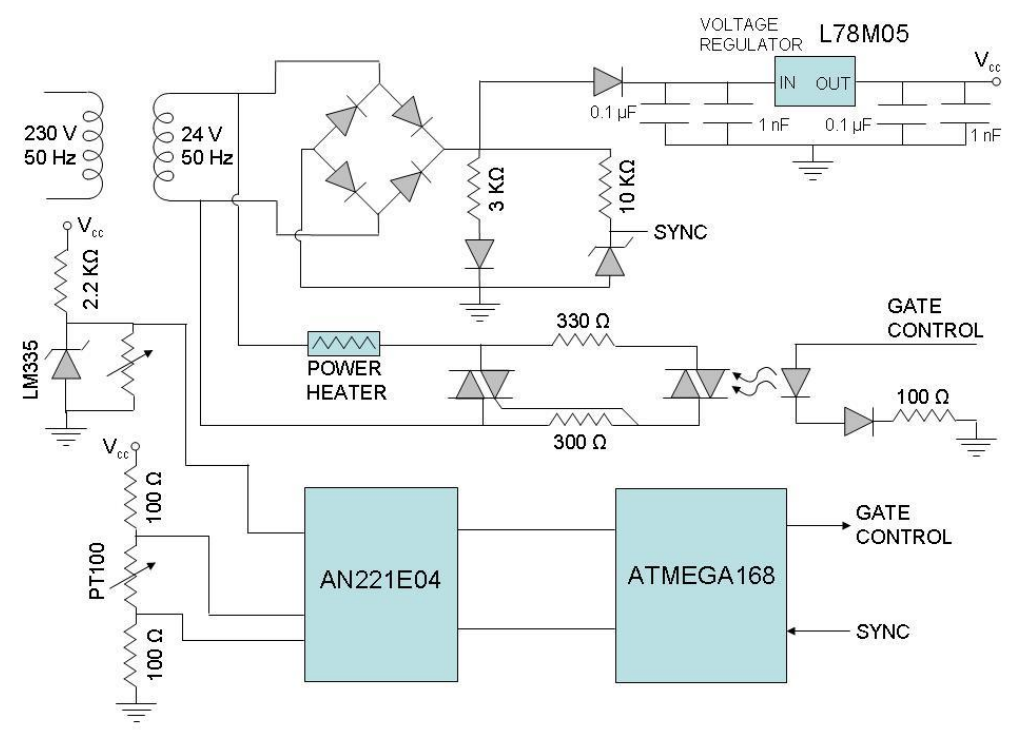

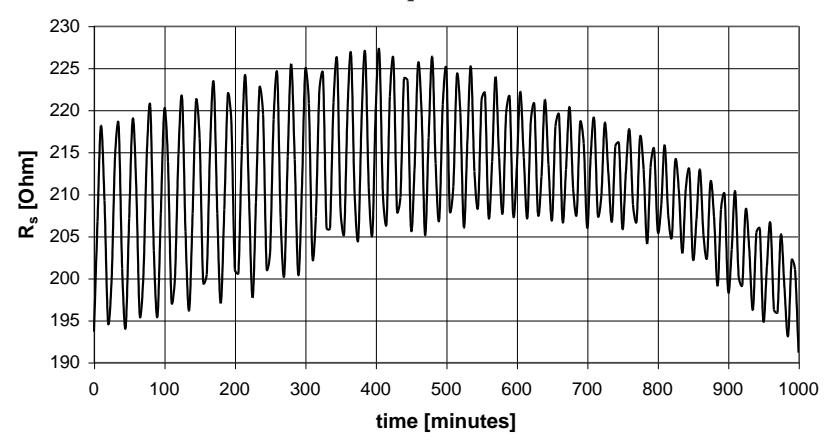

(b)

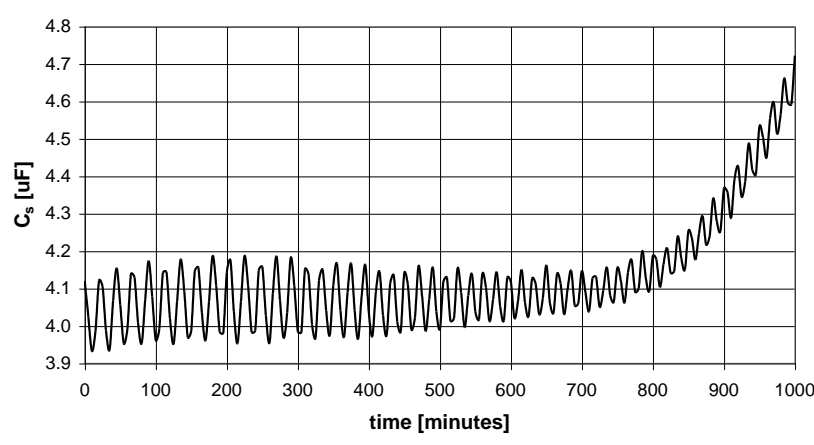

(c)

Fig. 3 


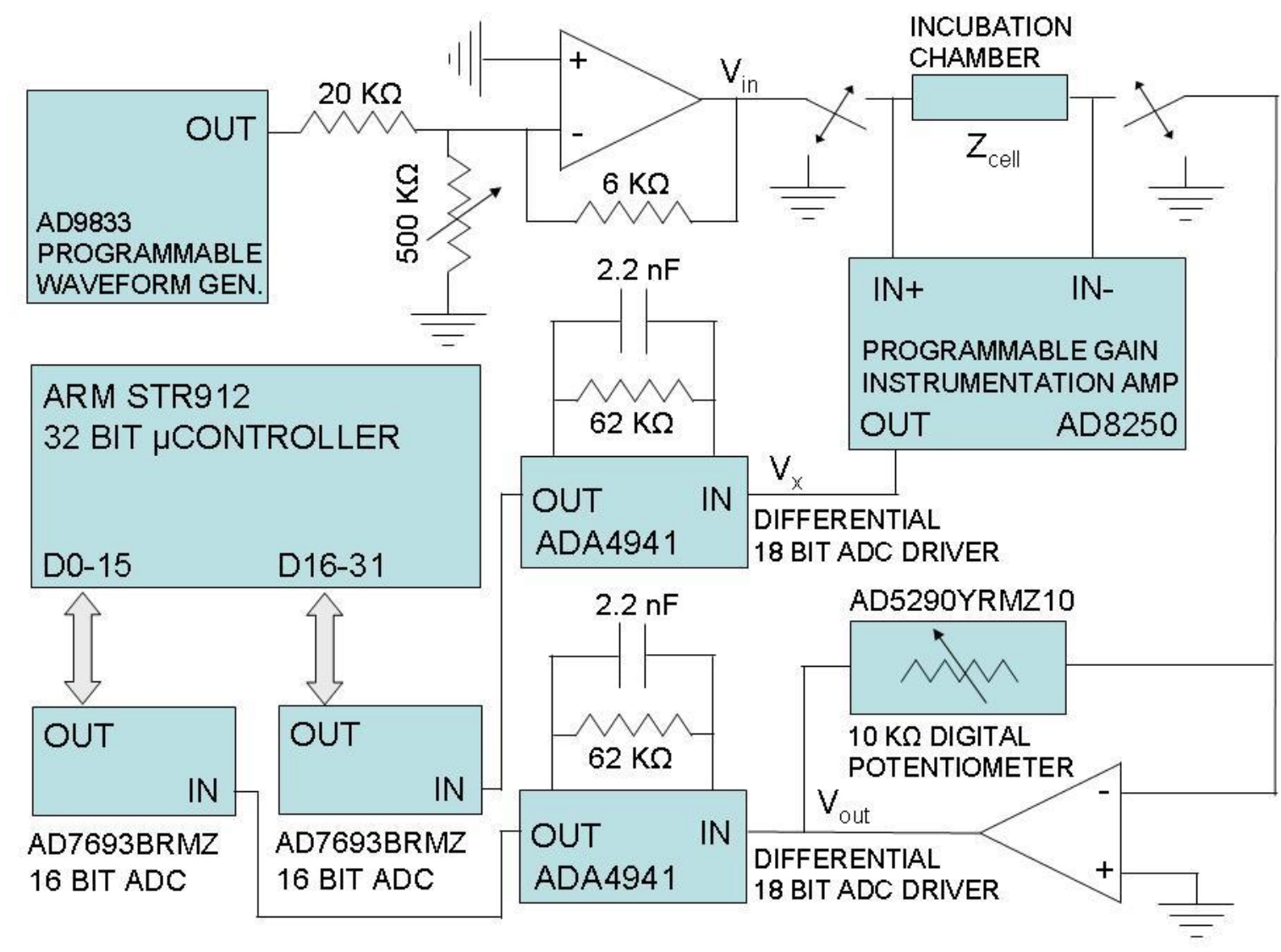

(a)

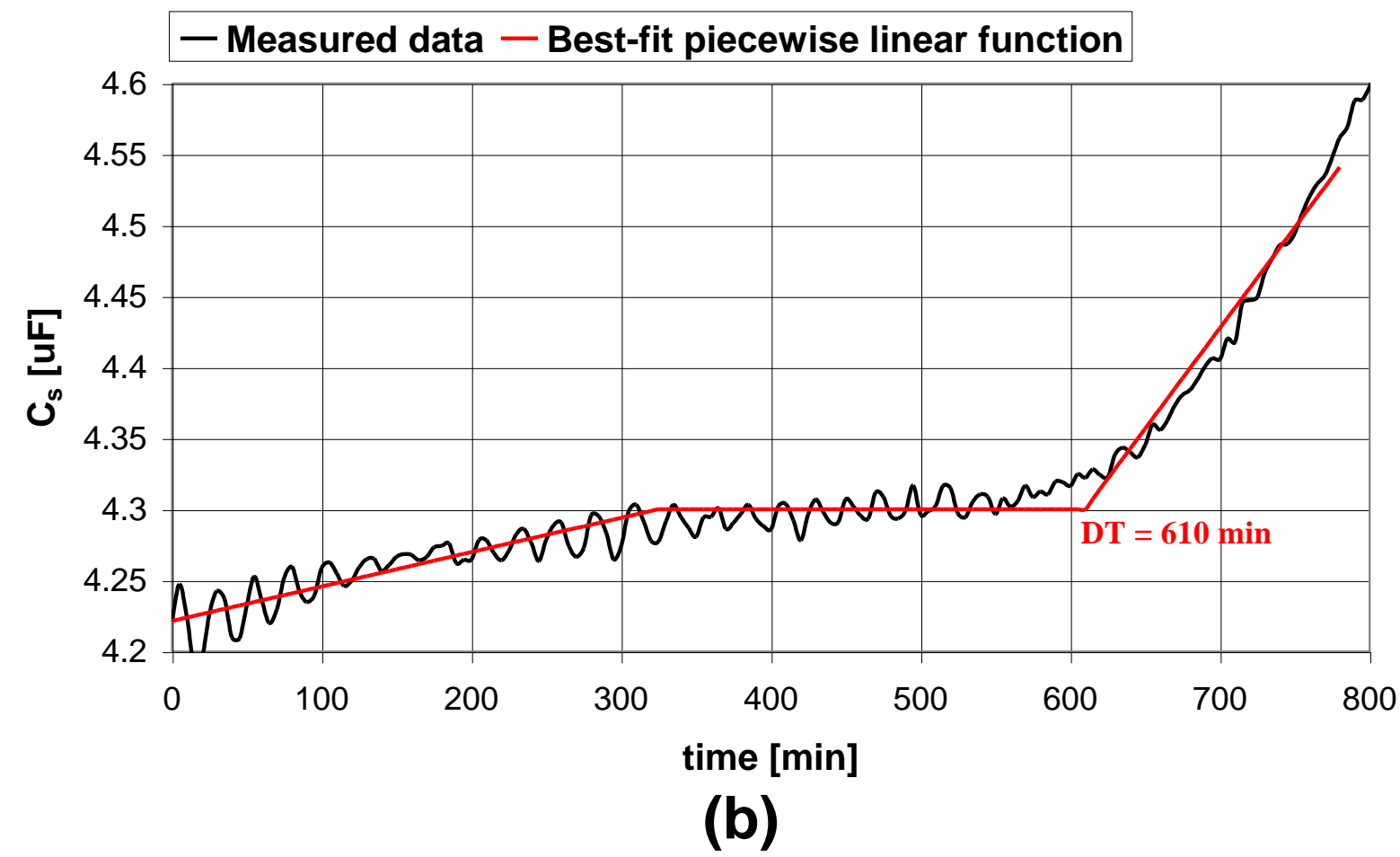

Fig. 4 


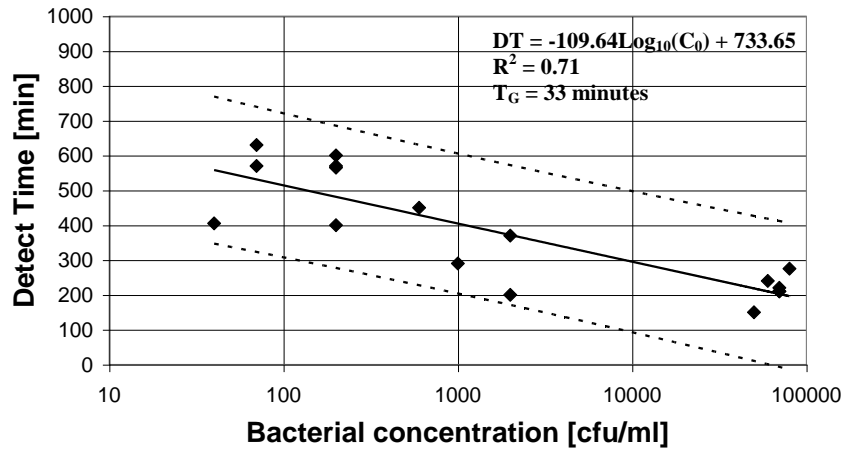

(a)

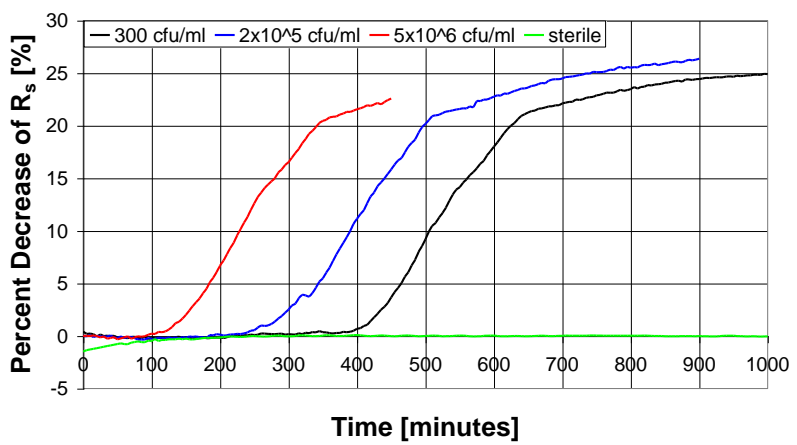

(c)

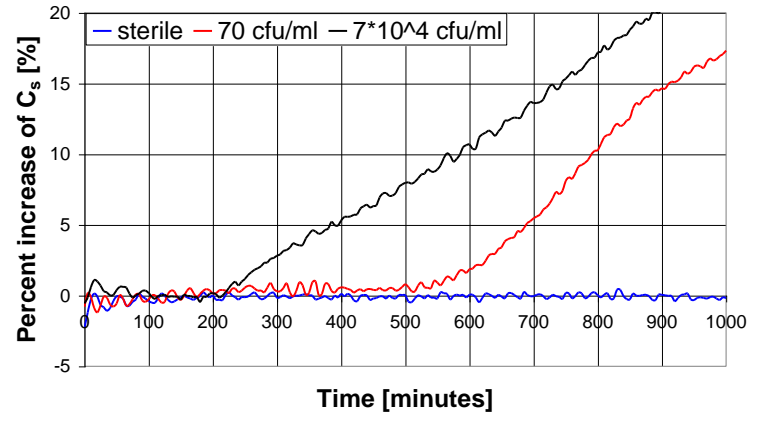

(b)

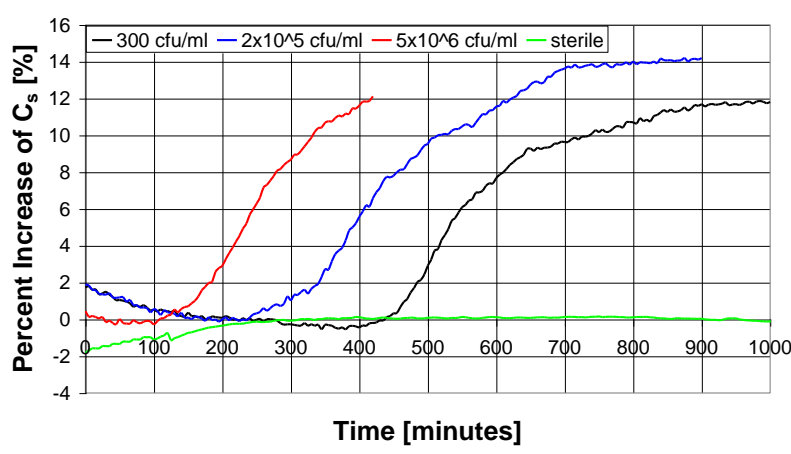

(d)

Fig. 5 